\title{
Prenatal Caffeine Damaged Learning and Memory in Rat Offspring Mediated by ARs/PKA/CREB/BDNF Pathway
}

\author{
Yongmei LI ${ }^{1 *}$, Wenna ZHANG ${ }^{1 *}$, Ruixiu SHI ${ }^{1}$, Miao SUN ${ }^{1}$, Lubo ZHANG ${ }^{2}$, Na LI ${ }^{1}$, Zhice XU $^{1,2}$ \\ *These authors contributed equally to this work. \\ ${ }^{1}$ Institute for Fetology, First Hospital of Soochow University, Suzhou, China, ${ }^{2}$ Center for Perinatal \\ Biology, Loma Linda University, CA, USA
}

Received March 12, 2018

Accepted June 26, 2018

On-line September 11, 2018

\section{Summary}

Prenatal exposure to caffeine can cause developmental problems. This study determined chronic influence of prenatal caffeine at relatively higher doses on cognitive functions in the rat offspring. Pregnant Sprague-Dawley rats (4-month-old) were exposed to caffeine $(20 \mathrm{mg} / \mathrm{kg}$, twice a day) for whole pregnancy from gestational day 4. Fetal and offspring body and brain weight was measured. Learning and memory were tested in adult offspring with Morris water maze. Learning and memory-related receptors were measured. The exposure to prenatal caffeine not only caused fetal growth restriction, but also showed long-term effects on learning and memory in the offspring. The caffeine offspring exhibited longer escape latency and path length in navigation testing. The number of passing the target was significantly reduced in those offspring. The expression of adenosine $A_{1}$ and $A_{2 A}$ receptors, nuclear PKA $C_{a}, C_{\beta}$ subunits, and PCREB were significantly increased in the fetal and neonatal brain, and suppressed in the hippocampus of the adult offspring. The expression of BDNF and TrkB were reduced regardless of various ages. The results suggest that intrauterine programming dysfunction of adenosine receptors and the down-stream of CAMP/PKA/pCREB system may play an important role in prenatal caffeine induced cognition disorders in the adult offspring.

\section{Key words}

Caffeine - Spatial cognition • PKA • Fetal growth restriction • Adenosine receptors

\section{Corresponding authors}

Z. Xu and N. Li, Institute for Fetology, First Hospital of Soochow University, Suzhou 215006, China. Fax: +86 51265238350. E-mail: xuzhice@suda.edu.cn or 52smrehab@163.com

\section{Introduction}

Since the concept of fetal origins of adult health/diseases was introduced about 30 years ago (Barker and Osmond 1986), extensive evidence has been accumulated to demonstrate that fetal adaptation to adverse factors or uterine environments may result in programming of long-term health problems after birth (Kuang et al. 2014, Li et al. 2015). Caffeine, a xanthine alkaloid, widely existed in coffee or tea, is consumed by $68-74 \%$ of pregnant women at an average intake of 125-193 mg/day (Frary et al. 2005). Chronic caffeine exposure in gestation can accumulate the chemical in the fetal brain (Wilkinson and Pollard 1993), causing low birth weight or risk of premature birth (Brent et al. 2011). Moreover, prenatal exposure to caffeine was reported to affect neurobehavioral development in the offspring. Low dose of approximately $10 \mathrm{mg} / \mathrm{kg} /$ day caffeine administration led to decreased locomotor activity in both juvenile and adult rat offspring following prenatal caffeine exposure (Hughes et al. 1991, Zimmerberg et al. 1991). However, Soellner et al. (2009) reported that there was no functional deficit in the Morris water maze by low dose of prenatal caffeine in the offspring. The effects of caffeine should be assessed depending on the doses used. Notably, addictive users and heavy drinkers of coffee are common. Whether high concentrations of prenatal caffeine exposure could impact on long-term learning and memory in adulthood is worth for investigation.

The hippocampus plays important roles in brain functions, including learning and memory (Lever et al. 
2002). Caffeine acts by inhibiting adenosine receptor (ARs) $\mathrm{A}_{1}$ and $\mathrm{A}_{2 \mathrm{~A}}$ in the brain (Fredholm et al. 2005). The primary second messenger of adenosine receptors is adenylate cyclase (AC), which catalyzes ATP into cyclic adenosine monophosphate (cAMP). cAMP-dependent protein kinase A (PKA) plays pivotal roles in the consolidation of spatial and non-spatial long-term memories. The dissociated catalytic (C) subunits of PKA could phosphorylate cAMP response element binding protein (pCREB) on serine 133 when cAMP sequential and cooperative bind to the regulatory (R) subunits. pCREB modulate transcription of LTP-related genes (Abel and Nguyen 2008), such as brain-derived neurotrophic factor (BDNF). Thus, PKA signaling is important for the hippocampus-dependent memory. BDNF is essential for growth, survival, and neuronal cell differentiation (Huang and Reichardt 2001). It is involved in the pathophysiology of Alzheimer's disease, Huntington's disease (Ma et al. 2015) and Parkinson's disease (Khalil et al. 2016). Through binding to neural receptor protein-tyrosine kinase- $\beta$ (TrkB), BDNF/TrkB also represents a major player in learning and memory formation by the regulation of neuroplasticity (Panja and Bramham 2014, Bekinschtein et al. 2014).

The present study hypothesized that relatively higher doses of prenatal caffeine might show long-term impact on the development of learning and memory, probably by affecting related receptors and cAMP/PKA/CREB signaling factors, as well as $\mathrm{BDNF} /$ TrkB in the hippocampus of the offspring. The hypothesis was tested using different ages of the offspring rats (fetus, neonates, and young-adult).

\section{Materials and Methods}

\section{Experimental animals}

All procedures and protocols were approved by the Institutional Animal Care and Use Committee and in accordance with the Guidelines for the Care and Use of Laboratory Animals.

Sprague-Dawley rats (250-280 g) were obtained from Soochow University Experimental Animal Center. All rats were housed in a controlled environment of temperature $22^{\circ} \mathrm{C}$ and a $12 \mathrm{~h}$ light/dark cycle, with free access to water and standard rat food. The day after mating was designated as gestational day (GD) 1 if vaginal plug was observed. Pregnant rats were randomly divided into two groups. Caffeine group (16 mothers) was provided with caffeine $(20 \mathrm{mg} / \mathrm{kg}$, Sigma-Aldrich, twice daily) via subcutaneous injection from GD4 to GD21, and physiological saline was used for the control group (16 mothers).

\section{Offspring experiments}

Pregnant rats (GD 21) were anesthetized with sodium pentobarbital $(100 \mathrm{mg} / \mathrm{kg}$; Hengrui Medicine, Jiangsu, China). After cesarean section delivery, fetal brain and body weight was measured (the litter size was 9 to $13, \mathrm{n}=30$ rats from 6 mothers/group). Natural delivery was allowed for other pregnant rats. All rats were raised in the same environment. Offspring (14-dayold, $\mathrm{n}=30$ rats from 6 mothers/group) was anesthetized, brain and body weight was measured. The other male offspring was raised to 4-month-old ( $\mathrm{n}=30$ rats from 6 mothers/group) for behavioral and biochemistry testing.

\section{Spatial water maze}

The Morris water maze (MWM) was used to assess spatial learning and memory as reported (Morris 1984). For water maze acquisition, the rats were trained to locate a submerged platform $(26 \mathrm{~cm}$ in height and $10 \mathrm{~cm}$ in diameter) in a circular white pool $(0.46 \mathrm{~m}$, depth; and $1.2 \mathrm{~m}$, diameter). Water was made opaque by addition of nontoxic white paint. The pool was divided into four quadrants. There were 4 acquisition trials each day with training lasting for 7 days and the position of the cues was not changed during testing. Each trial was started by placing a rat facing toward the wall. A trial was ended until the rat climbed on the hidden platform with all 4 paws or until $120 \mathrm{~s}$ elapsed. If the rats could not find the platform, they were guided to the platform and sit on it for $15 \mathrm{~s}$ before being removed and dried with a towel. In the end, the latency and path length for swimming to the platform were measured.

The retention test started at $24 \mathrm{~h}$ after the last day of the acquisition training. Rats were placed in the pool facing the wall in a randomly determined quadrant and allowed to swim within a controlled time (120 s). The platform was not present, and retention measures during the probe test included time spent in the target quadrant and number of target approaches. Swim speed was also measured. All activities of rats in the testing were monitored, recorded, and analyzed using MT-200 water maze video tracking system (Taimeng, Chengdu, China).

\section{ELISA analysis}

Brain tissue was homogenized with $20 \%$ 
ethanol in phosphate buffer solution (PBS), then centrifuged at $3,000 \mathrm{~g}, 4{ }^{\circ} \mathrm{C}$ for $5 \mathrm{~min}$. Supernatants were collected for analysis using an ELISA kit (JIMIAN Industrial, Shanghai, China) following the manufacturer's protocol. Briefly, $50 \mu \mathrm{l}$ standard sample was added into the standard sample well, containing $40 \mu \mathrm{l}$ sample dilution and $10 \mu \mathrm{l}$ testing sample (final dilution is 5 -fold). The antigen-coated wells were then incubated for $40 \mathrm{~min}$ at $37^{\circ} \mathrm{C}$, following a five times' washing with buffer. Then, the antigen-coated wells were incubated with $50 \mu \mathrm{l}$ of HRP-conjugate reagent for $30 \mathrm{~min}$ at $37^{\circ} \mathrm{C}$. The unbound antibodies were washed away with washing buffer, and then incubated with Chromogen Solution. After incubation for $15 \mathrm{~min}$ at $37^{\circ} \mathrm{C}$ in dark, $50 \mu$ of stop solution was added to each sample, and the absorbance at $450 \mathrm{~nm}$ was determined. Data were handled in a blind manner.

For ELISA test of PKA $\mathrm{C}_{\alpha}, \mathrm{C}_{\beta}$, and pCREB, nuclear extracts were prepared with the method below. In brief, brain tissue was homogenized in 10 volumes of buffer C (in mM): HEPES-NaOH ( $\mathrm{pH} 7.9$ ) 10, containing $\mathrm{KCl}$ 10, EDTA 1, EGTA 1, DTT 5, sodium fluoride (NaF) 10, sodium pyrophosphate $10, \mathrm{Na}_{3} \mathrm{VO}_{4} 1$, sodium $\beta$-glycerophosphate 10, PMSF 1, pepstatin A $1.25 \mu \mathrm{g} / \mathrm{ml}$, leupeptin $10 \mu \mathrm{g} / \mathrm{ml}$ and aprotinin $2.5 \mu \mathrm{g} / \mathrm{ml}$. Following the addition of $10 \%$ Nonidet $\mathrm{P}-40$ for a final concentration of $1 \%$, the homogenates were centrifuged at $15,000 \mathrm{~g}$ for $5 \mathrm{~min}$. Pellets were washed in three volumes of buffer $\mathrm{C}$, and centrifuged at 15,000 $\mathrm{g}$ for $5 \mathrm{~min}$. The pellets were then suspended in one volume of buffer $\mathrm{D}$ (in mM): HEPES NaOH (pH 7.9) 20, $\mathrm{NaCl} 400$, EDTA 1, EGTA 1, DTT 5, NaF 10, sodium pyrophosphate $10, \mathrm{Na}_{3} \mathrm{VO}_{4} 1$, sodium $\beta$-glycerophosphate 10, pepstatin A $1.25 \mu \mathrm{g} / \mathrm{ml}$, leupeptin $10 \mu \mathrm{g} / \mathrm{ml}$, aprotinin $2.5 \mu \mathrm{g} / \mathrm{ml}$, and PMSF 1, and centrifuged at 15,000 $\mathrm{g}$ for 5 min. The supernatant was stored at $-80^{\circ} \mathrm{C}$ as the nuclear extract.

\section{Data analysis and statistics}

Data were analyzed using the program Prism (GraphPad). The water maze data were analyzed using two-way analysis of variance followed with Bonferroni post hoc test. Other data were analyzed using t-test. Results were expressed as mean $\pm \mathrm{SEM}$, and $\mathrm{P}<0.05$ was considered statistically significant.

\section{Results}

\section{Body weight, brain weight, and litter size}

No significant changes were observed in body weight between normal (CON) and prenatal caffeine offspring (CAF) groups at 4 month old. The body weight of CAF offspring was significantly reduced at GD21 and PD14 (Fig. 1a). Brain weight was reduced in the CAF at PD14 and 4 month old, while no significant difference was found at GD21 (Fig. 1b). The treatment used in the present study did not induce significant differences in weight of the pregnant mothers between the two groups. The number of pups per litter and their sex was similar between the control and experimental groups (Table 1). a

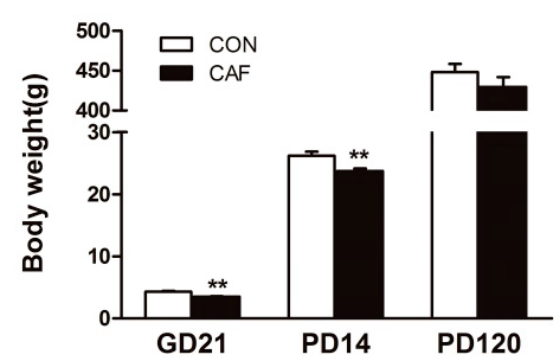

b

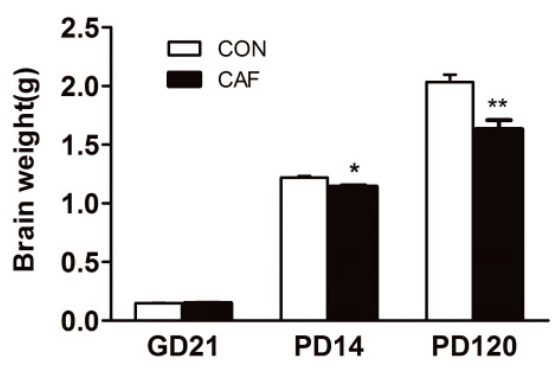

Fig. 1. The brain (a) and body weight (b) in the offspring (for GD21, $\mathrm{n}=60$ from 6 litters each group; for PD14, $n=50$ from 5 litters each group; for PD120, $\mathrm{n}=30$ from 5 litters each group). * $\mathrm{P}<0.05 ; * * \quad \mathrm{P}<0.01$ vs. the control.

Table 1. The effect of prenatal caffeine on weight gain of mothers, number of pups per litter and their sex.

\begin{tabular}{lcccc}
\hline Treatment & Weight gain of mothers & Number of pups per litter & Males & Females \\
\hline Control & $79.04 \pm 4.719$ & $10.78 \pm 1.63$ & $5.2 \pm 0.37$ & $5.6 \pm 0.51$ \\
Caffeine & $76.54 \pm 5.345$ & $10.29 \pm 2.16$ & $5.2 \pm 0.39$ & $5.6 \pm 0.34$ \\
\hline
\end{tabular}

$\mathrm{n}=60-62$ rats from 6 mothers. 


\section{Spatial memory performance in the MWM}

To assess whether exposure to caffeine in pregnancy affected behavioral functions in the adult offspring, behavioral tests was conducted. Time to find the platform was getting shorter when the course went on for all rats. The CAF offspring exhibited longer escape latency and longer path length during testing in a hidden platform-learning phase (Fig. 2). The escape latency was significantly increased in the CAF offspring from day 1 to day 5 compared with the control, and the path length was significantly increased at day 1 to day 3 (Figs $2 a$ and 2b).

In the probe trial (retention test), there was no significant difference in the time spent in the target approaches, however, the number of target quadrant approaches was significantly less than that of the control (Figs 2c and 2d).

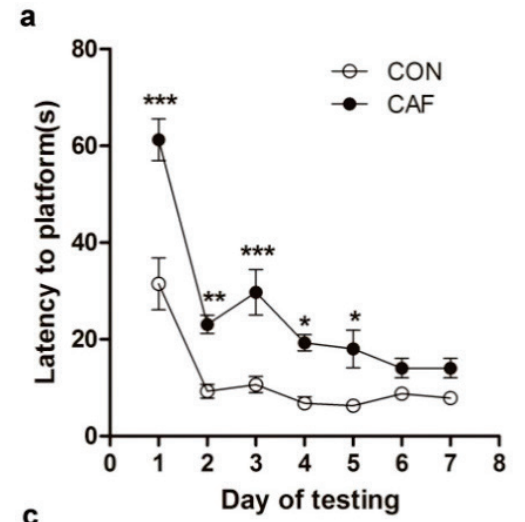

C
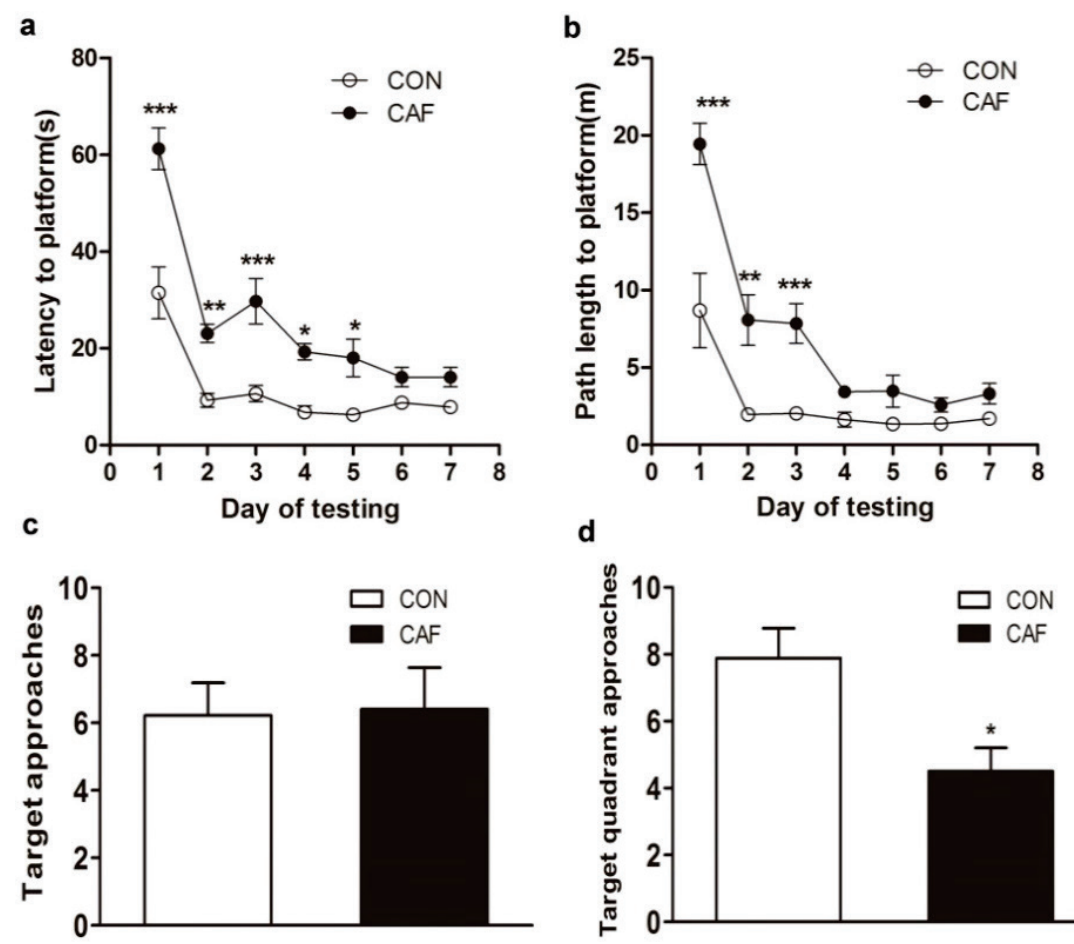

d

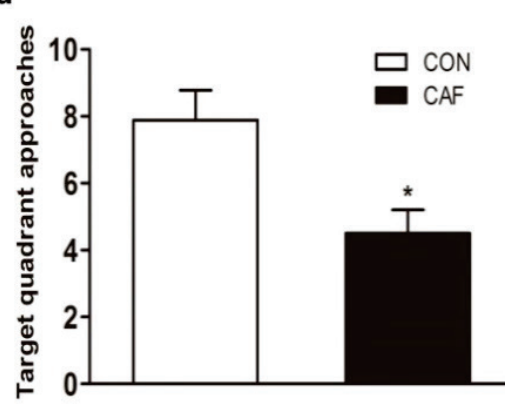

Fig. 2. The effect of prenatal caffeine exposure on behavior performance in the 4-month-old offspring. Escape latency (a) and path length (b) in MWM. Time spent in target approaches (c) and target quadrant (d) in the retention test. $n=10$ each group. $* \mathrm{P}<0.05, * * \mathrm{P}<0.01$, $* * * \mathrm{P}<0.001$ vs. the control.

\section{Adenosine receptors and $\mathrm{PKA}$ pathway proteins in the fetal and neonatal offspring}

The expression of adenosine $A_{1}$ and $A_{2 A}$ receptors

In contrast with that in the young adult brain, the protein expression of $A_{1}$ and $A_{2 A}$ receptors were increased in the CAF group at GD21 and PD14 (Fig. 3a). The ratio of $A_{2 A} / A_{1}$ was significantly raised (Fig. 3b).

\section{cAMP content, PKA subunits, and $p C R E B$}

Unlike the young adult offspring, there was an enhanced cAMP production in the CAF offspring at GD21 and PD14 (Fig. 3c), and the increased protein expression of nuclear PKA $\mathrm{C}_{\alpha}$ and $\mathrm{C}_{\beta}$ (Fig. 3d). Additionally, the pCREB level was also augmented in CAF at both GD21 and PD14 (Fig. 3d).

\section{$B D N F / \operatorname{TrkB}$}

The CAF offspring at GD21 and PD14 expressed lower BDNF and TrkB compared to that in the control (Fig. 3e).
Adenosine receptors and $P K A$ pathway proteins in the young adult offspring

The expression of adenosine $A_{1}$ and $A_{2 A}$ receptors

Both the expression of adenosine $\mathrm{A}_{1}$ and $\mathrm{A}_{2 \mathrm{~A}}$ receptors were decreased in the $\mathrm{CAF}$ at 4 month old (Fig. 4a), and the ratio of $\mathrm{A}_{1} / \mathrm{A}_{2 \mathrm{~A}}$ also was reduced (Fig. 4b).

\section{cAMP content, PKA subunits, and $p C R E B A$}

Significant decrease in cAMP content was found in the hippocampus of the CAF offspring (Fig. 4c). The expression of PKA $C_{\alpha}$ and $C_{\beta}$ protein was reduced (Fig. 4d). The expression of pCREB also was significantly decreased (Fig. 4d).

\section{$B D N F / \operatorname{TrkB}$}

Both the expression of BDNF and TrkB were significantly reduced in the hippocampus of the CAF offspring (Fig. 4e). 
a

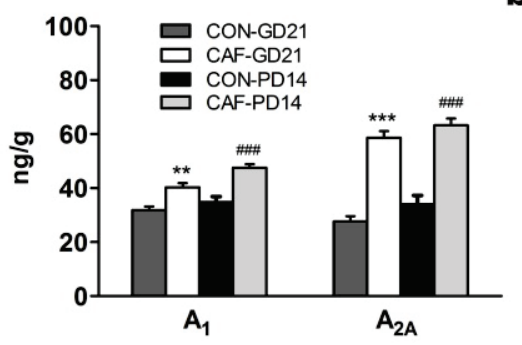

b

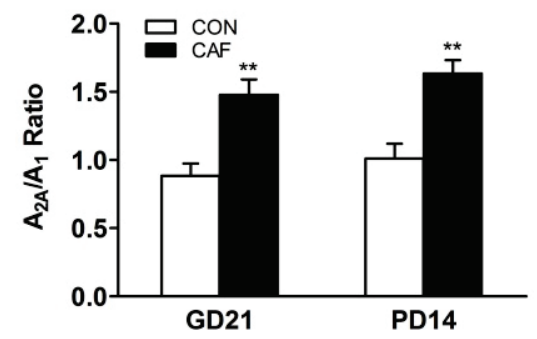

C

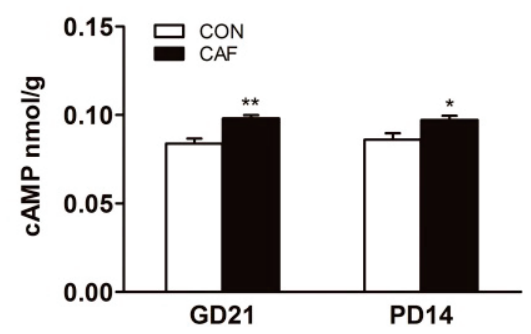

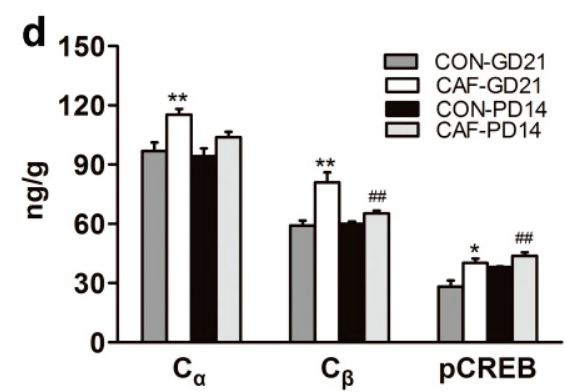

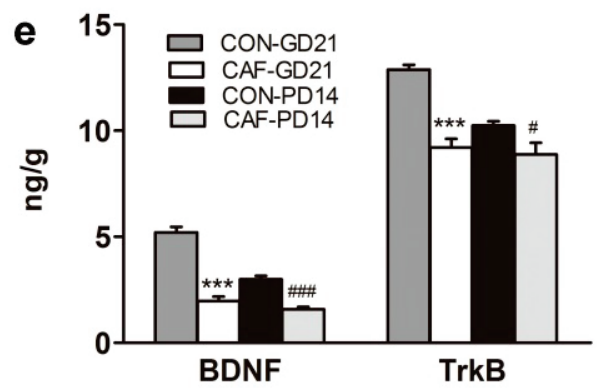

Fig. 3. The expression of adenosine $A_{1}, A_{2 A}$ receptors and CAMP/PKA/CREB/BDNF/TrKB cascade protein in the brain of fetuses and 14-day-old offspring. $\mathbf{a}$, protein expression of $A_{1}$ and $A_{2 A}$ receptors. $\mathbf{b}$, Ratio of $A_{2 A / A 1}$ receptor. $\mathbf{c}$, cAMP content of hippocampus from the two group. d, protein expression of PKA subunits $\left(C_{a}\right.$ and $\left.C_{\beta}\right)$ and pCREB. e, protein expression of BDNF and TrkB. $n=8-12$ each group. $* \mathrm{P}<0.05, * * \mathrm{P}<0.01, * * * \mathrm{P}<0.001$ vs. the control.
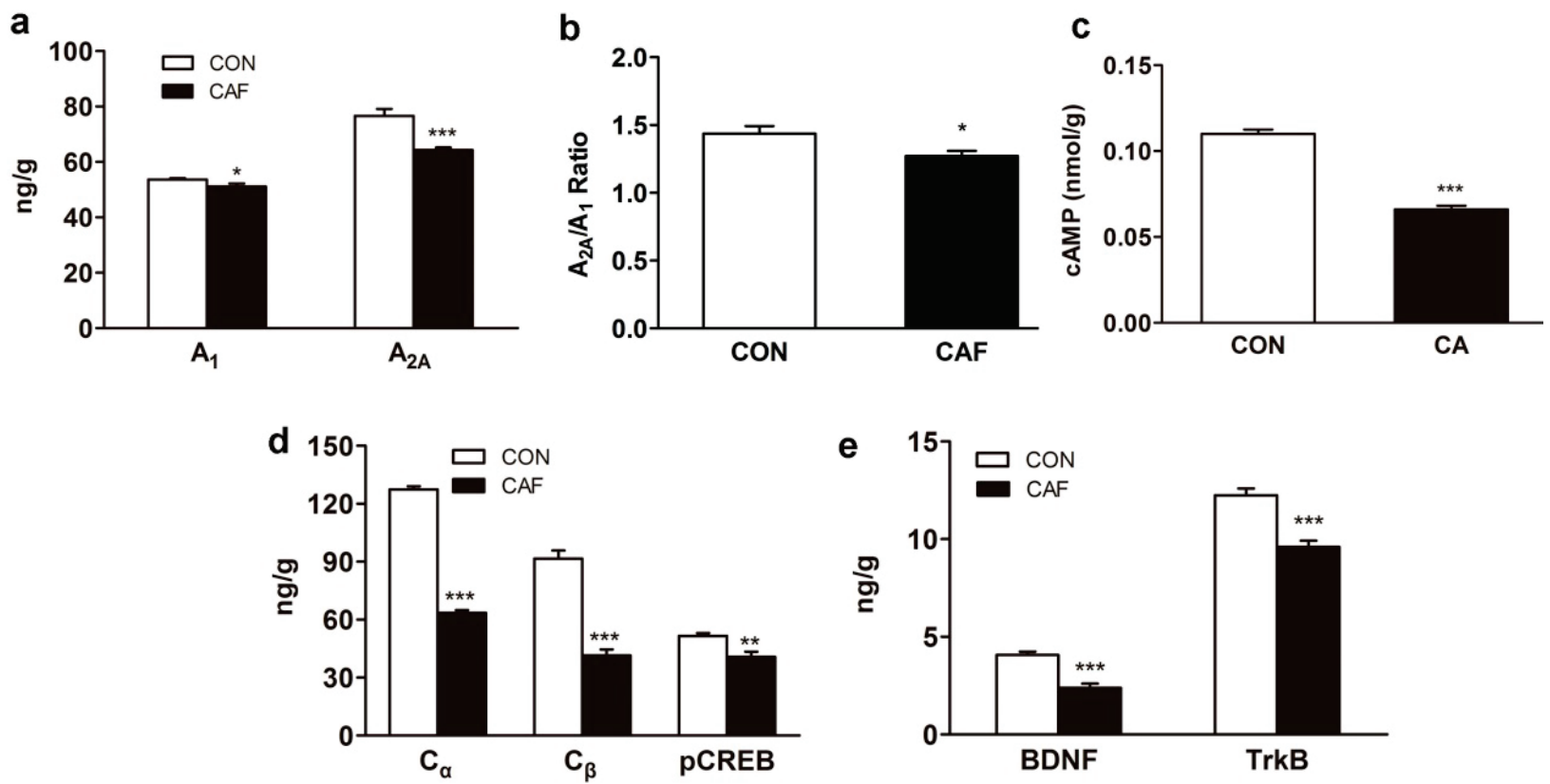

Fig. 4. The expression of adenosine $A_{1}, A_{2 A}$ receptors and CAMP/PKA/CREB/BDNF/TrKB cascade protein in the hippocampus of young adult offspring. $\mathbf{a}$, protein expression of $A_{1}$ and $A_{2 A}$ receptors. $\mathbf{b}$, ratio of $A_{2 A / A 1}$ receptor. $\mathbf{c}$, cAMP content of the hippocampus. d, protein expression of PKA subunits $\left(\mathrm{C}_{a}\right.$ and $\left.\mathrm{C}_{\beta}\right)$ and pCREB. e, protein expression of BDNF and TrkB. $\mathrm{n}=12$ each group. $* \mathrm{P}<0.05, * * \mathrm{P}<0.01$, $* * * \mathrm{P}<0.001$ vs. the control.

\section{Discussion}

The present study determined the influence of chronic caffeine exposure during gestation on the hippocampus-regulated behavior in the young adult (4-month-old), neonatal (2-week-old) offspring as well as in the fetal rats, and found: 1) the learning and memory in the young adult offspring were damaged, 2) the expression of BDNF and TrkB was reduced in the adult, neonatal offspring, and fetuses exposed to prenatal 
caffeine, 3) ARs/PKA/CREB signaling pathway was down-regulated in the young adult hippocampus, while that was up-regulated in the CAF fetal and neonatal brain.

In the present study, relatively higher doses of caffeine caused low body weight in the fetus as that reported (Liu et al. 2012). Moreover, the neonatal weight at 2 weeks after birth was still lower than that of the control, while this difference disappeared in the adult offspring. These data suggest that exposure to relatively higher caffeine during pregnancy not only hurt fetal development, but also influence neonatal growth. However, the body weight could become normal later if caffeine was not continued in postnatal life. An interesting phenomenon was noted regarding the impact of prenatal caffeine on the brain. Fetal brain weight was unchanged by caffeine in pregnancy, the weight was reduced in the brain of both neonatal and adult offspring, indicating long-term influence of relatively heavy caffeine in pregnancy could affect brain development, which might be caused by chronic damage induced by the caffeine that can easily pass the placenta and into the fetal body and accumulated in the brain. Why fetal brain weight could be rescued while postnatal brain weight was affected is worth of further investigations in future.

To understand whether and how the brain could be injured by relatively higher doses of caffeine, functional testing on the brain should be reasonable. The present study performed behavioral exams on the offspring. The experiments revealed that the CAF offspring exhibited longer path length toward the hidden platform, associated with an increase of escape latency, indicating damaged learning ability. In addition, the retention test showed the number of target approaches was significantly reduced, suggesting memory was injured. Previous study suggested that lower doses of caffeine had no significant effects on the Morris water maze functions in the offspring (Soellner et al. 2009). This study added new information regarding the chronic influence of relatively high doses of caffeine on learning and memory in the young adult offspring. The immediate question raised then was what was possible mechanisms underlying the functional changes in the offspring brain and their behavior. Although multiple causes could be involved in the mechanisms, the ARs/cAMP/pCREB/BDNF signaling pathway was considered in the present study, due to a series of studies have shown the link between caffeine and learning/memory as well as those molecules in the brain
(Abel et al. 2008, Fredholm et al. 1999).

Previous study demonstrated that the expression of adenosine $A_{1}$ receptors was significantly increased in the fetal rats after maternal caffeine treatments (Marangos et al. 1984, Etzel and Guillet 1994, Gaytan and Pasaro 2012). The present study showed increased $A_{1}$ receptors in the fetal brain following exposure to caffeine in pregnancy, suggesting caffeine used in pregnant mothers could impact on certain receptors in the fetal brain. Compared to $A_{1}$ receptors, there were fewer studies on a relationship between prenatal caffeine and adenosine $\mathrm{A}_{2 \mathrm{~A}}$ receptors in fetuses and offspring. Our study showed an increase in protein expression of $\mathrm{A}_{2 \mathrm{~A}}$ receptors in the fetal brain, which was inconsistent with the minor effect on fetal $\mathrm{A}_{2 \mathrm{~A}}$ receptors reported by Aden et al. (2000). The difference could be due to different caffeine dosage used. In Aden's study, the dose of caffeine given was mild to moderate $(0.3 \mathrm{~g} / 1$ in drinking water, equivalent to about 2 cups a day). However, since addictive users often use significantly higher doses and some people drink more coffee daily, our study designed a protocol of $20 \mathrm{mg} / \mathrm{kg}$ caffeine, twice a day, for total caffeine of $40 \mathrm{mg} / \mathrm{kg} / \mathrm{day}$ in rats. Based on the dose-conversion correlation between humans and rats (human: rats $=1.00: 6.17$ ), $40 \mathrm{mg} / \mathrm{kg} /$ day roughly equivalent to 4 cups of coffee (a cup of coffee contains nearly $150 \mathrm{mg}$ of caffeine on average) (ReaganShaw et al. 2008). The present study added new information that too much coffee intake in mothers or heavily using caffeine in pregnancy would stimulate more expression of both $A_{1}$ and $A_{2 A}$ receptors in the fetal brain.

The present study found that prenatal caffeine may affect the development of fetal brain via an increase of the drug binding site adenosine receptors. Activation of adenosine receptors initiates the post-receptor signal transduction involved in cAMP/PKA/CREB, which was demonstrated to play an important role in learning and memory (Fredholm et al. 1999, Takeo et al. 2003, McGuire et al. 2005, Zhao et al. 1995). We then tested the down-stream targets of PKA pathway. Generally, adenosine receptor subtypes have been classically characterized by the adenylate cyclase effector system, which utilizes cAMP as a second messenger. The $A_{1}$ receptors, coupled with $G_{i}$ proteins, inhibit adenylate cyclase, leading to a decrease in cellular cAMP levels, while the $A_{2 A}$ receptors, coupled to $G_{s}$ proteins and activate adenylate cyclase, leading to an increase in cellular cAMP levels (Poulsen et al. 1998). Although both $A_{1}$ and $A_{2 A}$ receptors were increased by prenatal caffeine, the expression of cAMP, however, was 
increased in the fetus following maternal treatments of caffeine. This could be caused by the increased ratio of $A_{2 A} / A_{1}$, making intracellular cAMP increased. PKA is a tetrameric protein composed of two regulatory subunits and two catalytic subunits $\left(\mathrm{C}_{\alpha}, \mathrm{C}_{\beta}\right.$ and $\left.\mathrm{C}_{\gamma}\right)$. Among the three catalytic subunits, $C_{\alpha}$ and $C_{\beta}$ are localized preferentially in the hippocampus (Takeo et al. 2003). cAMP binds to PKA regulatory subunits, therefore releasing catalytic subunits, permitting phosphorylase activity of PKA. The present study demonstrated that both the nuclear protein of $\mathrm{C}_{\alpha}$ and $\mathrm{C}_{\beta}$ were increased at GD21 in the fetuses exposed to maternal caffeine, which could be due to the augmented up-stream second messenger - the cellular cAMP level. Those results suggested that the increased expression of pCREB in nucleus, since the liberation and subsequent translocation of PKA-C subunits into the nucleus, determined the stoichiometry and kinetics of CREB phosphorylation (Hagiwara et al. 1993). pCREB is a core component of the molecular switch, converting short-term memory to long-term memory, and nuclear pCREB acts as a transcription factor regulating $\mathrm{BDNF}$ in response to drugs. Protein analysis showed that pCREB was significantly increased in the brain of both the fetus and neonatal offspring at postnatal 2 weeks, indicating pCREB signal was more active following prenatal exposure to higher doses of caffeine. Interestingly, pCREB protein expression in the hippocampus of the adult offspring was turned to the opposite direction, significantly decreased. There must be inner mechanisms underlying that the increased pCREB during early developmental periods was turned into the decreased level at the late life stage, which deserves new investigations. Our interpretation for the finding is that prenatal insults such as higher doses of caffeine caused acute responses in the fetal and neonatal brain via activation of pCREB. Over-activity of pCREB and related signaling may induce damage in the brain as chronic consequences such as the suppressed expression found in the hippocampus. Notably, previous studies (Kuang et al. 2014) showed prenatal insults induced apoptosis in the offspring brain.

The present study measured the protein expression of BDNF and its specific receptor, TrkB, in the fetus and offspring. We found that the expression of BDNF and TrkB in the brain were significantly reduced in the fetus, neonatal and adult offspring. There could be several possibilities underlying the suppressed BDNF and $\mathrm{TrKB}$ in the fetal and neonatal offspring. First, there may exist other pathways regulating the expression of BDNF without involvements of pCREB. Second, the increased pCREB caused signaling imbalance in the body, which may directly or indirectly affect expression of other molecules such as BDNF. This study presents what were exactly observed, and provides information that is worth further investigated.

The BDNF/TrkB receptor complex plays critical roles in developmental processes, regulation of neuro-, glio-, and synaptogenesis, neuroprotection, and controlling of short- and long-lasting synaptic interactions that influence mechanisms of memory and cognition (Foltran and Diaz 2016, Sasi et al. 2017, Messaoudi et al. 2002, Gruart et al. 2006, Whitlock et al. 2006). Mariga et al. (2015) reported that reduction of BDNF in the cultured rat hippocampal neurons was related to decreased expression of the genes that are functionally linked to vesicular trafficking and synaptic communication. The pattern of changes in gene expression was similar to the profile observed in Alzheimer's disease and cognitive impairment. Similarly, prenatal caffeine caused learning and memory dysfunction in the young adult offspring, as well as suppressed BDNF and TrkB in the brain, indicating an increased susceptibility to cognitive impairment and Alzheimer's disease.

The similar pattern of expression of adenosine receptors and the down-stream targets of cAMP/PKA/CREB signaling in the fetus and offspring was noted in the present study. The expression of adenosine $\mathrm{A}_{1}$ and $\mathrm{A}_{2 \mathrm{~A}}$ receptors, and the cAMP/PKA signaling were significantly enhanced in the brain of the fetus and 2-week-old offspring, while the same molecules were degraded in the adult hippocampus later, accompanied by an impairment in learning and memory in adulthood. The over-activity might cause damage, inducing the suppressed signaling in the brain. In addition, it can be considered that prolonged agonist exposure of $\mathrm{G}$ protein-coupled receptors could result in a progressive loss of the receptors (down-regulation), whereas too much antagonist exposure might cause increased receptor levels (Böhm et al. 1997). Gestational exposure to higher doses of caffeine may inhibit actions of adenosine in the fetal brain as acute responses, and over responses may alter the caffeine binding sites adenosine receptors and its post-receptor pathways, causing persistent alterations in the brain.

In conclusion, the present study showed that high doses of caffeine used in pregnancy not only injured 
learning and memory capabilities in the offspring, but also caused an over-activity of up-regulated ARs/cAMP/CREB signaling in the fetal and young rat brain. Importantly, that over-activities in the brain eventually was tuned into long-term damage of the signaling pathway in the hippocampus evidenced as suppressed expression of the key signaling in regulations of the cognitive functions. To the best of our knowledge, this was the first demonstration of the influence and possible mechanism of higher doses of prenatal caffeine on fetal, neonatal and adult brain associated with injured learning and memory. The novel data generated may offer new ideas for early prevention and treatments for learning disability resulted from abnormal development during early life stages.

\section{Conflict of Interest}

There is no conflict of interest.

\section{Acknowledgements}

This study is supported by The Natural Science Foundation of China (81500322) and Suzhou Science and Technology Project (SYS201606); Jiangsu Province's Key Discipline/Laboratory of Fetal Medicine.

\section{References}

ABEL T, NGUYEN PV: Regulation of hippocampus-dependent memory by cyclic AMP-dependent protein kinase. Prog Brain Res 169: 97-115, 2008.

ADEN U, HERLENIUS E, TANG LQ, FREDHOLM B: Maternal caffeine intake has minor effects on adenosine receptor ontogeny in the rat. Brain Pediatric Res 48: 177-183, 2008.

BARKER DJ, OSMOND C: Infant mortality, childhood nutrition, and ischaemic heart disease in England and Wales. Lancet 1: 1077-1081, 1986.

BEKINSCHTEIN P, CAMMAROTA M, MEDINA JH: BDNF and memory processing. Neuropharmacology 76: 677-683, 2014.

BOHM SK, GRADY EF, BUNNETT NW: Regulatory mechanisms that modulate signalling by G-protein-coupled receptors. Biochem J 322: 1-18, 1997.

BRENT RL, CHRISTIAN MS, DIENER RM: Evaluation of the reproductive and developmental risks of caffeine. Birth Defects Res B Dev Reprod Toxicol 92: 152-187, 2011.

ETZEL BA, GUILLET R: Effects of neonatal exposure to caffeine on adenosine A1 receptor ontogeny using autoradiography. Brain Res 82: 223-230, 1994.

FOLTRAN RB, DIAZ SL: BDNF isoforms: a round trip ticket between neurogenesis and serotonin? J Neurochem $\mathbf{1 3 8}$ : 204-221, 2016.

FRARY CD, JOHNSON RK, WANG MQ: Food sources and intakes of caffeine in the diets of persons in the United States. J Am Diet Assoc 105: 110-113, 2005.

FREDHOLM BB, BÄTTIG K, HOLMÉN J, NEHLIG A, ZVARTAU EE: Actions of caffeine in the brain with special reference to factors that contribute to its widespread use. Pharmacol Rev 51: 83-133, 1999.

FREDHOLM BB, CHEN JF, CUNHA RA, SVENNINGSSON P, VAUGEOIS JM: Adenosine and brain function. Int Rev Neurobiol 63: 191-270, 2005.

GAYTAN SP, PASARO R: Neonatal caffeine treatment up-regulates adenosine receptors in brainstem and hypothalamic cardio-respiratory related nuclei of rat pups. Exp Neurol 237: 247-259, 2012.

GONZALEZ A, MOYA-ALVARADO G, GONZALEZ-BILLAUT C, BRONFMAN FC: Cellular and molecular mechanisms regulating neuronal growth by brain-derived neurotrophic factor (BDNF). Cytoskeleton (Hoboken) 73: 612-628, 2016.

GRUART A, MUNOZ MD, DELGADO-GARCIA JM: Involvement of the CA3-CA1 synapse in the acquisition of associative learning in behaving mice. J Neurosci 26: 1077-1087, 2006.

HAGIWARA M, BRINDLE P, HAROOTUNIAN A, ARMSTRONG R, RIVIER J, VALE W, TSIEN R, MONTMINY MR: Coupling of hormonal stimulation and transcription via the cyclic AMP-responsive factor CREB is rate limited by nuclear entry of protein kinase A. Mol Cell Biol 13: 4852-4859, 1993.

HUANG EJ, REICHARDT LF: Neurotrophins: roles in neuronal development and function. Annu Rev Neurosci 24 : 677-736, 2001. 
HUGHES RN, BEVERIDGE IJ: Behavioral effects of exposure to caffeine during gestation, lactation or both. Neurotoxicol Teratol 13: 641-647, 1991.

KHALIL H, ALOMARI MA, KHABOUR OF, AL-HIESHAN A, BAJWA JA: Relationship of circulatory BDNF with cognitive deficits in people with Parkinson's disease. J Neurol Sci 362: 217-220, 2016.

KUANG H, SUN M, LV J, LI J, WU C, CHEN N, BO L, WEI X, GU X, LIU Z, MAO C, XU Z: Hippocampal apoptosis involved in learning deficits in the offspring exposed to maternal high sucrose diets. $J$ Nutr Biochem 25: 985-990, 2014.

LEVER C, WILLS T, CACUCCI F, BURGESS N, O'KEEFE J: Long-term plasticity in hippocampal place-cell representation of environmental geometry. Nature 416: 90-94, 2002.

LI N, LI Y, GAO Q, LI D, TANG J, SUN M: Chronic fetal exposure to caffeine altered resistance vessel functions via RyRs-BKCa down-regulation in rat offspring. Sci Rep 5: 13225-13236, 2015.

LIU Y, XU D, FENG J, KOU H, LIANG G, YU H, HE X, ZHANG B, CHEN L, MAGDALOU J, WANG H: Fetal rat metabonome alteration by prenatal caffeine ingestion probably due to the increased circulatory glucocorticoid level and altered peripheral glucoseand lipid metabolic pathways. Toxicol Appl Pharmacol 262: 205-216, 2012.

MA Q, YANG J, LI T, MILNER TA, HEMPSTEAD BL: Selective reduction of striatal mature BDNF without induction of proBDNF in the zQ175 mouse model of Huntington's disease. Neurobiol Dis 82: 466-477, 2015.

MARANGOS PJ, BOULENGER JP, PATEL J: Effects of chronic caffeine on brain adenosine receptors: regional and ontogenetic studies. Life Sci 34: 899-907, 1984.

MARIGA A, ZAVADIL J, GINSBERG SD, CHAO MV: Withdrawal of BDNF from hippocampal cultures leads to changes in genes involved in synaptic function. Dev Neurobiol 75: 173-192, 2015.

MCGUIRE SE, DESHAZER M, DAVIS RL: Thirty years of olfactory learning and memory research in Drosophila melanogaster. Prog Neurobiol 76: 328-347, 2005.

MESSAOUDI E, YING SW, KANHEMA T, CROLL SD, BRAMHAM CR: Brain-derived neurotrophic factor triggers transcription-dependent, late phase long-term potentiation in vivo. J Neurosci 22: 7453-7461, 2002.

MORRIS R: Developments of a water-maze procedure for studying spatial learning in the rat. J Neurosci Methods 11: 47-60, 1984.

PANJA D, BRAMHAM CR: BDNF mechanisms in late LTP formation: A syntheis and breakdown. Neuropharmacology 76: 664-676, 2014.

POULSEN SA, QUINN RJ: Adenosine receptors: new opportunities for future drugs. Bioorg Med Chem 6: 619-641, 1998.

REAGAN-SHAW S, NIHAL M, AHMAD N: Dose translation from animal to human studies revisited. FASEB $J$ 22: 659-661, 2008.

SASI M, VIGNOLI B, CANOSSA M, BLUM R: Neurobiology of local and intercellular BDNF signaling. Pflugers Arch 469: 593-610, 2017.

SOELLNER DE, GRANDYS T, NUÑEZ JL: Chronic prenatal caffeine exposure impairs novel object recognition and radial arm maze behaviors in adult rats. Behav Brain Res 205: 191-199, 2009.

TAKEO S, NIIMURA M, MIYAKE-TAKAGI K, NAGAKURA A, FUKATSU T, ANDO T, TAKAGI N, TANONAKA K, HARA J: A possible mechanism for improvement by a cognition-enhancer nefiracetam of spatial memory function and cAMP-mediated signal transduction system in sustained cerebral ischaemia in rats. Br J Pharmacol 138: 642-654, 2003.

WHITLOCK JR, HEYNEN AJ, SHULER MG, BEAR MF: Learning induces long-term potentiation in the hippocampus. Science 313: 1093-1097, 2006.

WILKINSON JM, POLLARD I: Accumulation of theophylline, theobromine and paraxanthine in the fetal rat brain following a single oral dose of caffeine. Brain Res Dev Brain Res 75: 193-199, 1993.

ZHAO WQ, POLYA GM, WANG BH, GIBBS ME, SEDMAN GL, NG KT: Inhibitors of cAMP-dependent protein kinase impair long-term memory formation in day-old chicks. Neurobiol Learn Mem 64: 106-118, 1995.

ZIMMERBERG B, CARR KL, SCOTT A, LEE HH, WEIDER JM: The effects of postnatal caffeine exposure on growth, activity and learning in rats. Pharmacol Biochem Behav 39: 883-888, 1991. 